\title{
CIRCULAR ECONOMY AND CREATE NEW VALUES - RECYCLING, RENEWABLE ENERGY, ECOLOGY
}

\author{
Stanka Djurić, ${ }^{1}$ Ljiljana Stošić Mihajlović, ${ }^{2}$ Svetlana Trajković ${ }^{3}$ \\ ${ }^{1}$ Tax Administration, Office Kragujevac, Republic of Serbia \\ ${ }^{2,3}$ College of applied professional studies, Vranje, Republic of Serbia \\ stanka.djuric@purs.gov.rs, mihajlovicp@ptt.rs, cecasvtr@yahoo.com
}

\section{Professional Paper \\ doi:10.5937/jouproman5-14306}

\begin{abstract}
The waste is a global problem of the protection of the planet. It was established that the strategy of Serbia and the European Union (EU). No urban environment that is completely solved the problem of waste. These are the technologies that municipal waste is completely recycled to the useful value is returned to the industry which is becoming an economic resource. The development of new technology realizes a complete recycling of mixed municipal waste. Politics, local government and citizens are to such efforts need to be supported and implemented. Development Techno MBO-T technology to achieve the goals of sustainable development, circular economy is achieved and targets "zero waste". The construction of standard factories for processing and recycling of municipal waste can be achieved through economic, environmental, energy and social development goals Serbia.
\end{abstract}

Keywords: circular economy, reversing logistics, recycling, renewable energy sources

\section{INTRODUCTION}

Recycling of industrial waste disposal of getting a simple procedure communal feet of waste in households and businesses. The delay in a container is carried out to further the process of recycling and reuse. Disposal and collection is carried out in the most economical and most convenient way. Deferred or separated waste is transported as quickly as possible from the site of disposal for recycling. Plants for recycling must be built as close as possible due to the reduction of transport costs. Recycling is done as soon as possible in controlled conditions no negative impact on the environment. Sorting of waste by use value and market needs in the industry. Harvesting raw materials with the least volume and the moisture content of the fuel. Costs of recycling municipal waste must be as small as possible per ton delivered waste processing. Processing of organic waste is intense biodegradation in time of 6-8 weeks. The procedure for processing wastes no pollution of water out of air. It is necessary to build the type of factory for processing mixed waste and pre-sorting. The control objectives are:

- obtaining more raw materials,

- more energy,

- more jobs.

The formation of transport models that integrate socio - economic data, data on land use, information on transport infrastructure, data on the characteristics of movement, information about the behavior of passengers and all information that may be relevant to various traffic analysis is the way to achieve sustainable development of cities. [1] 
Factory for processing of municipal solid waste to be built with larger landfills for recycling them. What is MBO-T technology industrial processing of mixed municipal waste developed and patented by the company, which is engaged in processing of waste? Technological combinations of mechanical, biological and thermal treatment processes (MBO-T), the processing of mixed municipal solid waste under controlled conditions of recycling and re-use of raw materials and energy as well as in industry. The construction of MBT-T we do not need a new landfill is not a device for purifying wastewater. The recycling of achieving political, economic and environmental objective, no citizen revolt, the satisfaction of all. The global objective is no climate change, there is no infectious disease citizens, create new social values, recorded a growth industry, get new raw material for the circular economy and get new energy for the development of the industry. Processing of waste in the MBT-T plant is eco-industry in order to "zero waste". Such projects financed from European funds and the World Bank. Waste treatment plant is paid for 5 years, a life time of at least 25 years. The construction of such processing factory price is much cheaper for the state, cities and citizens. MBO-T standard waste treatment plant is technological evolution in the management of mixed waste. Energy consumption per ton of processed mixed municipal waste is only 1 per ton. This is a sustainable future for the country and nature, and for the citizens of smaller jobs and a higher standard. Such projects serve the welfare of the whole society Composting is one of the oldest methods of recycling. The advantages of this natural biological process of waste disposal are forgotten for a long time, but there is a growing awareness of environmental protection, resulting in laws and increasing the cost of proper disposal. Composting has experienced a revival in many countries in the last century as a sensitive method of waste disposal. The most commonly used method is composting piles or furrows. Organic waste from different sources are mixed, placed in the grooves and breaks by means of controlled aerobiological process. The final product rich in nutrients is transferred over the areas that require fertilization and thus completes the cycle of food production. As a result of "green design", there was a "smart house". From the aspect of sustainable energy it uses most accessible and renewable energy. For us, it would be geothermal water, wind energy and solar energy, accumulates and conserves energy, integrates and combines energy systems, program control rationalize consumption, saves water, rainwater accumulates, recalculated water, control air quality in the home and the level of harmful emissions from home [2]

\section{TOWARDS INTEGRATION NEGOTIATIONS ON $\begin{array}{llll}\text { CHAPTER } & 27 & - & \text { THE }\end{array}$ ENVIRONMENT AND CLIMATE CHANGE \\ EUROPEAN AND}

Negotiations for Chapter 27 Environment and climate change will be one of the most demanding in the process of accession to the European Union, but also the most expensive because the implementation of the standards will require significant financial resources. 
The European Commission last year estimated that Serbia has made some progress in further aligning legislation with the EU in the field of waste, nature protection and climate change. The Ministry of Agriculture and Environmental Protection say that the post-screening document status and plans of transferring and implementing the EU acquits for Chapter 27, the environment and climate change, adopted, and then sent to the European Commission, Directorate General for the Environment. This document describes the understanding of the scope and complexity of Serbia in order to achieve full compliance with EU regulations. Serbia will achieve full compliance with most of the EU legislation provided for in Chapter 27, before accession. In the case of those Directives where the real is not possible to achieve full compliance by the date of accession, specific plans for implementation of the directive will be used as an instrument of policy implementation of the overall strategic direction defined by the National Strategy for approximation in the environmental field - stated in the Ministry. Post-screening document is designed to facilitate the assessment of the capacity of the European Union for Serbia to make progress towards the next stage of accession. It points to the vision of Serbia when it comes to overcoming the serious financial challenges related to the implementation of EU legislation in the environmental field. That the significant financial challenges to fulfill the requirement of Chapter 27 are considered by many European and domestic analysts. Our country will have a special focus on those provisions which are technically and financially demanding and whose implementation will be established on the date of accession to the EU but we will need additional time in order to reach European standards. These are the regulations for the enforcement of which we have provided large financial resources and mainly related to the construction of utility infrastructure. one of the major challenges for Chapter 27 is the system of financing of all necessary measures for the achievement and implementation of standards in the areas of waste and water management, prevention of industrial pollution, the system of chemicals management, nature protection - all of which must be achieved before the date of accession. In addition to finance, to meet the demands required the cooperation of all relevant institutions: To be well set up a system of economic instruments to be a strong horizontal cooperation among all competent institutions in all sectors, for the protection of the environment affects the development of industry, agriculture, public utilities sector health. Unfortunately, we have a situation that in 2015 abolished the dedicated nature of pollution and other benefits for the environment, but these funds do not solve burning issues, but it is consumed as determined by the Minister of Finance. The economic system represents a heterogeneous complex consisting of commercial entities, property relations, management and decision-making, information base upon which economic decisions are made, the objectives of decision-makers, results evaluation system operation, the foreign economic relations, the role of the state and the economy, and legal norms legal sub-system of economy, good business practices and other elements important for the functioning of the economy. [3] 


\subsection{EU FUNDS CHAPTER 27 - THE ENVIRONMENT AND CLIMATE CHANGE}

According to some estimates from the funds of the European Union, Serbia could withdraw EUR 1.2 billion for the negotiation process and Chapter 27 Environment and climate change. However, in the domestic leading experts, the biggest problem is ignorance in the field of writing and project management, as well as the provision of documentation. Note that we can count on the structural and cohesion funds EU LIFE program, as well as bank loans, for example. Loans from the European Investment Bank. But we must bear in mind that we are obliged to provide themselves need their own participation which is not small. Furthermore, we need projects, arranged project documents with all the necessary permits, and a good system of project cycle management, which now is our weak point. On the other hand, should not be considered to have a big expectations that we will easily get funds from EU funds. Basically some of the possibilities for application of these funds are open only for the republican authorities and municipalities, while for businesses and associations that space a lot of unknown and obscure. Everyone is talking that we can draw a lot of resources, and virtually no one explains how and in what way. It is necessary that someone from the EU Delegation and the Ministry of European Integration already hold a seminar or workshop where we would clearly presented programs and procedures explained how to apply for this funding. Now it all comes down to personal interests and surfing just to have found some competition. On the other hand, there is the question whether we have the capacity, as well as how we are skilled and capable to write projects for these funds. It is notable that in Serbia we all like to work independently, to avoid association and joint action, and that we can be very costly in performance with the EU funds.

\section{THE GREEN ECONOMY VS. CIRCULAR ECONOMY}

The green economy has huge potential in Serbia is generally known facts, and that we are in the field far behind the European Union. Even in countries in the region, plastic bags in supermarkets will be charged extra, a sorting and disposal of municipal waste is far simpler. Ecology, recycling, renewable energy are themes that have already been witnessed for decades, but the aspiration of our country to join the European Union will slightly accelerate the development of this segment of society. Negotiations for Chapter 27 Environment and climate change will be one of the most demanding in the process of accession to the EU, but also the most expensive because the implementation of the standards will require significant financial resources. As Serbia moves closer to EU expectations of economic experts that by studying ecology bring the largest number of jobs - around 150,000. Guided by the idea that the waste is not garbage, we have created this work related to the creation of new value through the cycle: recycling, renewable energy, ecology. We learned that as a result of conventional industry, other economic activities and people's habits Serbia now has 3,500 illegal dumps and only 8 regional sanitary landfills. 
In our country, generated nearly 8 million tons of waste per year, of which about 2.7 million utility. Recycles only 5$7 \%$, while annually supply worth 50 million euro's deposited on non-sanitary landfills. Renewable energy sources of the Republic of Serbia are significant and are estimated at 5.65 Mtoe per year, of which only $35 \%$ utilized. The biggest difficulty is the lack of money because the large initial investments, followed the legal procedures, the general lack of information, as well as the habits of people. However, there are good examples. These are companies that in their production processes incorporate modern solutions, reduce the use of raw materials in production, use alternative energy sources and more difficult to "zero" waste. Even appear and start-up companies that develop eco-innovations and solutions for "smart" cities. In the newsletter we presented and extremely high-quality solutions for converting waste water plants, hazardous waste treatment, innovative recycling technologies, environmentally friendly materials. Serbia as a state, obviously, puts the focus on ecology and reuse of materials, more business entities engaged in the green industry. It remains to be seen whether all these efforts remain in studies, analyzes, good practice examples and the like, or it will eventually all these potentials to be realized and in practice.

Solving environmental issues open space for the development of new "green" industries, but it will require new administrative staff for the implementation of regulations in Chapter 27, including requirements for monitoring, inspection and necessary equipment. We already have a need for a variety of experts who are familiar with this area, and it will be more of that. Our economy is not accustomed to the environmental costs, the need to valorize all possible negative effects and external costs. Will the state and the private sector to do something about the employment of more people involved in environmental issues, remains to be seen. The political will to change the current system of economy that does not care about the environment and climate change, to move to an economy that consumes no fossil fuels, which reduces the use of resources, based on reforestation, organic agriculture. The government could subsidies to stimulate "green jobs" as it now subsidizes the arrival of foreign firms and employment in them. As Serbia moves closer to EU expectations of economic experts that by studying ecology bring the largest number of jobs - around 150,000. Space for a green economy and employment potential has in distributed renewable energy, energy efficiency and recycling, organic farming and tourism. With us there is already a large number of so-called "green jobs and professions," such as waste collectors, recyclers, Editor of green areas, engineers, green building, breeders Gardens on roofs, workers specialized in wind energy, etc. More will be jobs for engineers, environment, biology-ecology, analysts Environment, managers to manage environmental risks, consultants for intervention in the environmental field, analysts for integrated resource management, economists, environmental lawyers and attorneys specializing in this area and others. It is important that people in Serbia recognize that dealing with environmental opportunity for the economic development of the country, not just the cost, as it represents mainly public. 
Therefore, it is worthwhile to establish a small business to deal with environmental problems and hire experts to perform these tasks well.

Circular Economy is an alternative to today's model of the economy that involves the uncontrolled exploitation of natural resources and material flow from the factory to the user via landfill. Figuratively it could be explained by an example that apples that you have not eaten, and began to rot, you can throw it in the trash or make them into pies. The characteristics of circular economy as the maximum utilization of the resources that are in use, which means that the waste from one industry does not end in a landfill or in nature, but it uses a different industry, as a raw material. In addition, it is one of the ways of fight against climate change. As a result of the conventional industry, the economy and habits of people in Serbia there are 3,500 illegal dumps and only 8 regional sanitary landfills. Recycles only $5-7 \%$ of the waste, and annually supplies worth 50 million euro's deposited on nonsanitary landfills. Circular Economy is based on several pillars:

- a lower consumption of natural resources;

- an extension of the product life, and the components of the materials used;

- massive use of renewable and recyclable resources;

- reducing emissions.

Guided by the principles of the present, the circular economy is a few steps away from the recycling techniques we know today. In fact, today is going to reduce the amount of material built into products, minimizing the consumption of energy and raw materials in production, product design suitable for maintenance, replacement, modification or repair, then the development of maintenance and servicing, preventing the by-products have become waste and, finally, the expansion of awareness among consumers about the possibilities of renting, borrowing or joint use - instead of ownership. Serbia is in the process of building its system of environmental management, by adjusting the legislative framework in this demanding field. However, although we are in the development phase of the system, perhaps it is now a good time to be in the national strategies and policies incorporate elements and principles of circular economy, but taking into account the level of economic development of the country and the state of the industry and the economy as a whole. In addition, it must be borne in mind that all of this costs money and that most of these costs pay for industry and citizens. Circular economy should contribute to sustainable development, environmental protection, conservation of resources and the health of people and it is the interest of all citizens and in Serbia. Although this concept is relatively new in our country there are good examples from practice.

In Serbia, there are dozens of good examples and success stories to apply some principles of the circular economy. These are companies that in their production processes incorporate modern solutions, reduce the use of raw materials in production, use alternative energy sources and more difficult to "zero" waste. Even appear and start-up companies that develop eco-innovations and solutions for "smart" cities. 
Today in Serbia, increasingly, not only talk but also works with "green" materials used in construction, then, we have examples of projects of electric cars, there are industries in their entire supply chain to promote the principles of sustainable development and how the report the widest The public. These are the so-called socially responsible companies that recognize that sustainable business for the modern key and take care of the safety and health of employees, but also to be a desirable neighbor who cares about their local environment. Today, competition is not measured only by the quality of products or services, and new technologies, but must take into account the company's reputation and ethical business through the prism of saving natural resources, environmental protection and active role in solving the most important problems in the local community.

In Serbia there are about 15 companies that report on their sustainable business according to the principles and standards that are internationally recognized. However, there are a number of small and medium-sized enterprises that follow them and learn from them, and our common task is to help these companies be more. The advantages of circular economy are large, but they are great investments. In the European Union Member States are in the adaptation period when the national activities apply instruments for the implementation of this new business concept. The waste industry, it is considered that the goals set ambitious and very demanding but are continuing negotiations on the harmonization of the positions of all stakeholders. This is a new challenge for the industry, including industrial waste. On this subject water intensive discussions within the framework of the European Union. So in June the planned conference in Paris on the theme "Driving Circularity in Europe's industries" with the participation of private industry, a number of European associations as well as representatives of the European Commission and decision-makers of Member States. The main theme of the conference is the implementation of the objectives and the improvement of work processes and new technologies to the industry adopted the EU policies on circular economy. All member states are required to implement the policies adopted at EU level through parliament, still with a certain time period for compliance and implementation. According to our interlocutor, the advantage of circular economy is the preservation of natural resources and the environment, the potential application of new technologies, new work processes and of course new jobs. According to estimates, still unofficial, it is expected that the implementation of the concept of operations in accordance with the circular economy provide 30,000 new jobs in Serbia. Good practice circular economy, and its development both at global and local level include: a better standard of society, preservation of natural DC Initiative and the health of the population.

\section{BETTER PAYMENT OF FEES AND CHANGE LEGISLATION CONTRIBUTE TO SOLVING ENVIRONMENTAL PROBLEMS AND NEW JOBS}

Contribute to solving environmental problems and new jobs Serbia annually produces about 100,000 tons of hazardous waste. 
This is primarily related to industrial waste, such as motor oil, tires, batteries, electronic and electrical devices after their useful life are hazardous waste. If not treated properly, because of the many hazardous substances contained may cause serious adverse effects on human health and the environment. A large number of hazardous substances affects the contamination of soil, water and atmosphere, and due to their carcinogenic properties indirectly because malignant diseases and other health damage in children and adults. In Serbia, thanks to the companies that manage hazardous waste annually treats about 60,000 tons of hazardous waste, including the collection, transport, depot wick and separation of hazardous materials from waste. Given the fact that in Serbia, but also in neighboring countries, there is no facility for final treatment of hazardous waste, hazardous materials treated under the strict terms of exports to EU countries where it is disposed of or treated in special plants. This principle applied by all EU countries, where the cost of waste treatment and permanent disposal shall be borne by the polluter in accordance with the European principle - the polluter pays eco tax payments. The potential for growth exists because it is recycling industry with its technology able to treat large quantities of hazardous waste. However, at this moment, as we face the problems of unstable funding we cannot think about the growth of recycling, but only about solving these problems. Explaining the problem of finances, it should be noted that the regulation of products that after use become special waste streams defined Production - that the polluter shall pay an eco fee of a few percent depending on the product types covering costs of hazardous waste management. However, not all pollutants diligent in paying Eco tax, as it is estimated that the annual charge only $30 \%$. Last year, from environmental taxes was collected 7.5 billion. The Ministry of Environmental Protection is aware that the improvement in the collection of environmental taxes can certainly improve the efficient and effective inter-sectored cooperation of the competent organizational unit of the Ministry in charge of environmental protection within the scope of its competence implement secondary legislation relating to the award of incentives, and agencies environmental protection. The relevant Minister has recently stated in the media that "leaked in a systematic way of dealing with this problem and are suing everyone who did not pay the eco-tax." While the law requires that funds collected from polluters have to spend on environmental protection, according to the president of the Association of Serbian Recycler for this purpose in our country are determined by only two billion. This amount is not enough, because unfortunately for 60,000 tons of hazardous waste annually takes about 3 billion pounds. The problem was created by abolishing the Fund for Environmental Protection in 2013. The quantities of processed waste grew and fees, in the absence of the body (the Fund), which is dealt with, do not harmonizing. The unpredictability of the business has significantly influenced the volume of recycling, staffing and financial parameters. In addition, there is a legal obligation which provides that hazardous materials from processed waste within 12 months permanently disposed of, and that is with us is only possible if they are exported from the country to the final treatment, for which at present there are not enough funds because care hazardous waste and its transport abroad is very expensive. 
The problems can be overcome if it would stabilize funding system, if $100 \%$ of polluters paid eco fee and if the money from the collection of eco-tax, as the law prescribes, returning to the field of environmental protection and therefore the one part, and the recycling industry.

Serbia annually produces about 100,000 tons of hazardous waste. This is primarily related to industrial waste, such as motor oil, tires, batteries, electronic and electrical devices after their useful life are hazardous waste. If not treated properly, because of the many hazardous substances contained may cause serious adverse effects on human health and the environment. A large number of hazardous substances affects the contamination of soil, water and atmosphere, and due to their carcinogenic properties indirectly cause malignant diseases and other health damage in children and adults. In Serbia, thanks to the companies that manage hazardous waste annually treats about 60,000 tons of hazardous waste, including the collection, transport, depot wick and separation of hazardous materials from waste. Given the fact that in Serbia, but also in neighboring countries, there is no facility for final treatment of hazardous waste, hazardous materials treated under the strict terms of exports to EU countries where it is disposed of or treated in special plants. This principle applied by all EU countries, where the cost of waste treatment and permanent disposal shall be borne by the polluter in accordance with the European principle - the polluter pays eco tax payments. The potential for growth exists because it is recycling industry with its technology able to treat large quantities of hazardous waste. However, at this moment, as we face the problems of unstable funding we cannot think about the growth of recycling, but only about solving these problems. Explaining the problem of finances, it should be noted that the regulation of products that after use become special waste streams defined manufacturer - that the polluter shall pay an eco fee of a few percent depending on the product types covering costs of hazardous waste management. However, not all pollutants diligent in paying Eco tax, as it is estimated that the annual charge only $30 \%$. Last year, from environmental taxes was collected 7.5 billion. The Ministry of Environmental Protection is aware that the improvement in the collection of environmental taxes can certainly improve the efficient and effective inter-sectored cooperation of the competent organizational unit of the Ministry in charge of environmental protection within the scope of its competence implement secondary legislation relating to the award of incentives, and agencies environmental protection. The relevant Minister has recently stated in the media that "leaked in a systematic way of dealing with this problem and are suing everyone who did not pay the eco-tax." While the law requires that funds collected from polluters have to spend on environmental protection, according to the president of the Association of Serbian Recycler for this purpose in our country are determined by only two billion. This amount is not enough, because unfortunately for 60,000 tons of hazardous waste annually takes about 3 billion pounds. The problem was created by abolishing the Fund for Environmental Protection in 2013. The quantities of processed waste grew and fees, in the absence of the body (the Fund), which is dealt with, do not harmonizing. 
The unpredictability of the business has significantly influenced the volume of recycling, staffing and financial parameters. In addition, there is a legal obligation which provides that hazardous materials from processed waste within 12 months permanently disposed of, and that is with us is only possible if they are exported from the country to the final treatment, for which at present there are not enough funds because care hazardous waste and its transport abroad is very expensive. The problems can be overcome if it would stabilize funding system, if $100 \%$ of polluters paid eco fee and if the money from the collection of eco-tax, as the law prescribes, returning to the field of environmental protection and therefore the one part, and the recycling industry.

\section{IT IS NECESSARY INVOLVING CITIZENS IN THE SYSTEM OF PRIMARY SELECTION OF PACKAGING}

By 2019, Serbia will have to collect and send to recycling $60 \%$ of packaging was opened to traffic. Are we going to meet this standard? For the full year 2016 target of $44 \%$, this year's goal is $50 \%$ and it is worth doing. To achieve the target of $60 \%$ which is recycled in the EU is crucial to involve citizens in the system of primary selection of packaging waste through the clear provisions of the Government to local governments related to statutory obligations. In this process, in addition to support the industry, which helps operators through the whole process, it is necessary to turn recycling industry through projects of setting up infrastructure for the collection of packaging waste, as well as the involvement of civil society in the work of mass education of citizens. Experiences in the end always had shown a high willingness of citizens to participate and separating waste, or the sensitivity of themselves on the unprofessional behavior of utility companies in the process of collecting this same separate packaging waste. It is impermissible for example. The truck with mixed waste inserted bags with separate management, and this was a rare case in the past. Of course, there is progress but the process is slower than we expected. Plans for 2017 are to continue the upward trend, primarily in cooperation with the government and relevant ministries in the work to improve the existing system, the introduction of criteria for the operator's work, clear-obligation guidance to local governments on a uniform system of primary selection, which make it easier for citizens of Serbia you can always identify where the waste is disposed of. We believe that the success made by Serbia, and that is that in the seven years since the beginning of the establishment of the system reaches even $50 \%$ of the quantity of recycled packaging waste, something that we should all be proud of. That leaves us another 50\%, which require more investment, use of EU funds in a transparent and balanced manner. It should continue its clients with full-service, to partner local governments and their utilities are supported and directed towards the best solutions, primarily in the interests of citizens and the state be a partner in improving the system of packaging waste management. In order to start the fight against the accumulated waste and pollution in the rivers of Serbia, made the first pilot project of partition dam for the collection of packaging waste on the river Raska in Batnjik. 
Bearing in mind that this is the first such model partition dam, planned to be in the next year, depending on water level fluctuations, analyzing the proposed model - stainless steel floating buoy with pouring basket to speed. It comes to the conclusion as to the best results, in order to implement the model in other river flows. It is expected that during the barrier dam be "flooded" and "stranded", which will give us the best insight into the behavior of the proposed solution, as it was planned from the beginning. Any change in water level is an opportunity for designers and contractors in the field determine what is necessary in order to harmonize dams and carrying the basket continuously operated in the collection of packaging waste. Unfortunately, this is not the dam "on" but that "like it or not", but a model that primarily not to violate regulations. The first month of its "life" was turbulent. Nature has decided to put us to the test. We learn and move on to new barriers to be crossed. The largest contribution to this project will be coming to the most optimal solution for the collection and protection of rivers from waste, which requires several months of monitoring and optimization. Setting these dams on the rivers of Serbia contributed to that they are cleaned and at the same time to educate citizens stop further pollution. In cooperation with the relevant ministry should work on setting up new mobile dams. For now, the already dammed have to go through all four seasons and then the best solution is placed on other rivers.

No less important is the question of who are the biggest problems faced by recyclers of packaging waste and where they see the solution to these problems? For recycling is important that there are sufficient quantities of collected raw materials that are needed to fill their production capacity. As for the waste collection network and expanding primary selection process to include greater quantities of packaging waste collected. What immediately makes it difficult for many to be the primary selection in Serbia to a higher level is the informal sector which is now much more active than it was in 2012, but it contributed to the purchase of the cities were opened by the recycler. As long as the informal sector has a safe place of sale of secondary raw materials taken from the collector container so long will it only increase. The focus is the development and improvement of primary selection of packaging waste management system and we will continue to work together with the state as a partner. The remaining $50 \%$ target will only be supplied if all activated together - and partner local governments and their utilities as well as private collectors and recyclers - and find the best solution for Serbia.

\subsection{RECYCLING OF PACKAGING WASTE AS A SEGMENT OF CIRCULAR ECONOMY}

At least 15,000 people in Serbia has been collecting waste for recycling. In addition, there are a couple of dozen small companies involved in the recycling of packaging waste and over a hundred involved in collecting it. When we look at the sector as a whole, including the informal collectors of recyclable materials, it is estimated that at least 20,000 people live on the recycling of packaging waste. In Serbia, the most recycled waste paper and plastic, especially PET bottles and polyethylene film. 
There are also facilities for the recycling of waste wood, glass, metal packaging, carton. The fact that public utilities continue to dispose of $95 \%$ of the collected garbage to landfills speaks not only does not treat waste in an environmentally responsible manner, but also as a country we do not recognize the potential for economic growth that lies in the processing of waste. For recycling of packaging waste, the key problem is that the packaging waste management system established set of green Act 2009 does not give the expected results. State's Law on packaging and packaging waste allows industry polluting companies to market products in packaging that becomes waste after use to override the system operator to establish themselves pay a fee for packaging which is intended for investment in infrastructure for the collection of packaging waste for recycling. However, such a set system increasingly resembles the situation that "goats kept cabbage", because it has shown that the primary interest of the bond of the economy to pay as little as possible, and today the fee for packaging waste that polluters pay not only the lowest in Europe, but also several times lower compared with the region. It is logical that therefore the investment in infrastructure for the collection of packaging waste are insufficient to be able to follow the planned growth of the national targets for recycling prescribed by the State in accordance with the objectives of the European Union or to provide development potential that lies in recycling. On the ground, they see the consequences of such a situation. Volume growth in most of the collection are virtually non-existent, and the largest percentage of waste recycled by our factory comes from the informal collectors that are in the gray zone. We came into a situation that industry polluters maintain the existing system and to fulfill its legal obligations through the work of the black economic groups who, without any financial or institutional support, collecting waste feed their families. This situation is unacceptable in the long term, and certainly can not be in the European Union with a system that can not respond to its requests. If the state of Serbia becoming an EU member, but fails to reach the prescribed targets for recovery and recycling of packaging and waste, not to close the wild and unsanitary landfill which has about 3,500 citizens of Serbia will have to pay expensive criminal penalties. Association for two years unsuccessfully requested that the Amendments to the Law on packaging and packaging waste edit an existing system to be able to follow the needs of the market and the EU accession process. Government and ministries have to define urgent measures for the improvement, or rather, rescue the existing system of packaging waste management. If this time the administration does not have a hearing and will to tackle the problems they are not just recyclers face, but also the entire waste management sector, we will have no choice but to seek the introduction of the deposit system as an alternative to the present. The deposit system, which is most similar bail system for returnable glass bottles, the consumer when buying products in plastic, glass bottles, cans pays his deposit returned when empty packaging brings to the store. Such a system exists in many European countries and ensures that collects and recycles up to $90 \%$ of packaging waste under the deposit system. 
Unfortunately, the industry of packaging placed on the market is the biggest opponent of the deposit even though it is more efficient than the existing one. The costs of introducing a deposit system requires an increase in fees that bond industry pays for the disposal of packaging products which after use environmentally sound, is their resistance to these changes logical.

\section{CREATE NEW VALUE}

\subsection{PLANT FOR TREATMENT OF HAZARDOUS WASTES AND CONVERTING WASTE INTO ALTERNATIVE FUELS DEFINED QUALITY}

How to solve the problem of waste treatment in Serbia? In Serbia, generated nearly 8 million tons of waste per year, of which about 2.7 million municipal waste. How do I waste in a container is not ready now for recycling, it is necessary to invest in waste sorting. The best solution is to invest in the sort of the single households, as well as in waste management infrastructure. The only way to take advantage of large amounts of waste that has to be on energy use. Energy utilization of wastes is normal in Western Europe. In contrast, Southern Europe has plants to obtain energy from waste because they require large investments, and the cost of care in these facilities is very high. Due to this fact the cement industry with its great potential can significantly help to reduce the amount of waste deposited at minimum cost. The cement industry in Serbia can dispose of about 350,000 tons of waste per year, and so it is visible as a solution for waste management and for the state and the professional public. The objective is to continue co-operation with companies and associations that deal with waste management, in order to position itself as a trusted partner who always finds optimal solutions.

Although it was announced that Serbia would receive a treatment plant for hazardous waste, it looks like it is "debilitate" location code. Since 2003, there were more attempts or initiatives for planning and construction of the physicalchemical treatment of hazardous waste, which are operated with the support of the European Union (CARDS program 20032004 and IPA 2009 program). Due to overwhelming public opposition, which would then lead to the absence of political support at the local level, all attempts to find a location for the construction of such a plant were suspended already in the initial stage. Future EU support for the continuation of the project would be determined by finding the location, which should be done prior to the spatial plan and detailed plan of regulation, so that the Ministry tries to continue the project implemented through a new IPA program. Since then no new activity on this project.

\subsection{TO SUPPORT GREATER USE OF BIOMASS STATES IN FOCUS}

The greatest potential of Serbia in renewable energy lies in biomass. [4] In this regard, there are ongoing projects which will provide an additional 500 megawatts of renewable energy sources and said that special attention should be paid to the use of biomass, which is our greatest potential. Serbia more "fancy" looking at wind and solar parks, as we see when we travel to, or ignore it that the greatest potential for biomass. 
If it is about 5.6 million tons of oil equivalent of our total potential of renewable energy sources, around 3.3 million is from biomass. Biomass should be far more in the spotlight and we as a ministry have been working on the promotion and will continue through the construction of small plants and investments in biomass and biogas, but primarily through the constant pressure to the district heating systems, should be added that the power plants are increasingly moving to the use of biomass.

In fact, since 2010, 11 biogas plants at a total capacity of about $12,967 \mathrm{MW}$ acquired the status of a temporary privileged producer of energy. In the past initiated several projects that will contribute to greater use of biomass for energy purposes. In the course of the project "Reducing barriers for rapid biomass market development in Serbia", within which were awarded grants for six new plants for combined production of electricity and heat from biomass and biogas, with a total installed capacity of 6.32 MW. Late last year, she began working in the first bio power plant from this program. Also, through the project of promoting the use of renewable energy biomass market development in Serbia, will be invested funds in the amount of EUR 100 million, and it is planned that the implementation of the project to start this year. The main investments relate to the installation of biomass boilers, heat pumps, hot water network reconstruction, construction of warehouses for the procurement of biomass and other equipment necessary for the supply of biomass, control systems and control in boilers, construction works.
As already mentioned, studies and analyzes show that biomass is the most significant renewable energy potential in Serbia is estimated at 3,405 Mtoe $^{1}$ per year, of which $55 \%$ rural and $45 \%$ woody biomass. The potential of wood mass amounts to 1.53 Mtoe. Forest biomass is the most common in the south and in central Serbia and its utilization rate is very high at $70 \%$. Estimated potential of agricultural residues from biomass crops, residues in orchards, vineyards and fruit processing is Mtoe 1.67 per year. Agricultural biomass is most common in the north of Serbia, the data of the Serbian Chamber. However, despite the wide distribution of its potential use in a negligible percentage of $2 \%$. - The potential of primary biodegradable waste is estimated at 205 thousand toe, municipal waste and waste edible oils and animal waste are estimated at a total amount of 0.043 million toe per year. The potential of biodegradable municipal waste at the moment, does not exploit.

Bio ethanol can be produced from cereals, potatoes, sorghum and Jerusalem artichoke, whose growing in Serbia there are about 100,000 hectares of marginal land.

Biodiesel can be produced from oil crops: sunflower, soybean and rapeseed, whose cultivation can be carried out on 350,000 hectares, which would allow an annual production of about 220,000 tons of biodiesel. Also, it is possible to collect about 10,000 tons of waste edible oil suitable for biodiesel production. - The situation in Serbia can be described lack of information of the main participants in the market about the benefits of biomass energy, the cost-effective technologies for the collection of waste biomass, the biomass quality improvement and logistics systems.

\footnotetext{
${ }^{1}$ Mtoe - ton of oil equivalent
} 
They did not fully familiar with advanced technologies using biomass, a major problem is the lack of biomass markets. As part of the project "Reducing barriers for rapid biomass market development in Serbia", implemented by the Serbian Chamber of Commerce, UNDP, the Ministry of Energy and Environment, was established portal 'Green Energy' that contains news about renewable energy and energy efficiency legislation and by-laws, regulations and standards authority of institutions, projects and sources of financing, terms of expertise does not work, the base of market participants, advertisements and other information relevant to doing business in Serbia in the sector. It is expected that the portal will contribute to the development and capacity building in the field of renewable energy and energy efficiency, promote competition and integrate biomass market participants - investors, design companies, contractors, distributors, equipment manufacturers, banks, government and civil society. Enabled and advertising companies and entrepreneurs operating in this area. Portal should provide future domestic and foreign investors information, guidance and support on how and under what conditions to develop, finance, build and manage a successful and profitable projects in the field of RES and EE.

Special attention was paid to the segment of trade in biomass, development of software, which allows the first online store in Serbia different types of biomass. Segment portal for trade with biomass, as a tool, it is very important for the development of the biomass market, which in our country is practically nonexistent and either takes place largely in a gray area. For the purposes of trade in biomass have been developed detailed specifications pro excerpts from wood and agricultural biomass, which include commercial codes, types of biomass, the corresponding units in which trading takes place, dimensions, moisture content etc. The range of products which are traded now includes woody biomass and wood products, and agricultural biomass and biomass originating from the food industry. We will continue working on increasing the range of products and bio liquids. The application for the trade of biomass is possible for customers and for vendors larger and more diversified offer (by species, types and quantities), unified bid (by species, types, assortments, packaging), standardized quality of products traded, easily understandable price, great speed shopping, access to small and large suppliers and customers, the savings in time and cost of sales, less need for inventory. PKS and further develop the portal and in the next phase is predestined and electronic commerce various types of biomass in Serbia.

\subsection{INVESTORS INTERESTED IN BUILDING WIND FARMS}

Since 2010, when the first time in Serbia established the legal framework with incentives ( "feed-in" tariffs) to May this year, were built new facilities for the production of electricity from renewable energy total installed capacity of about 90 MW 68 small hydropower plant of the total installed power of about 44,421 MW and 6 small hydro installed power of 4,375 MW, which have a status of temporarily privileged producer of energy; 106 solar power plant of $8,786 \mathrm{MW}$; 
3 MW wind power stations 17 and the wind power plant 6 , which have acquired the status temporarily privileged producer 482.86 MW of total power. Then, built 9 power plants on biogas total capacity of 10,332 MW and 2 biogas plants have acquired the status of a temporary privileged producer with total power of 2,635 MW. Installed and 9 CHP plants with a total installed capacity of about 10,948 MW.

As already mentioned, the potential of renewable energy sources of the Republic of Serbia are significant and are estimated at 5.65 Mtoe per year. More than $60 \%$ of the potential of biomass, which is approximately 3.4 Mtoe per year. Of these, 2.3 Mtoe is unused, and 1.1 Mtoe is already in use. Available technical hydro potential is 1.7 Mtoe per year, of which 0.8 Mtoe per year unused, and 0.9 Mtoe annually exploited potential. The estimated potential in geothermal energy is 0.2 Mtoe per year in wind energy 0.1 Mtoe per year while in the solar energy 0.2 Mtoe per year and 0.04 Mtoe per year in the biodegradable part of waste - data of the Serbian Chamber. The Republic of Serbia of any of the available technical potential of renewable energy sources already used by $35 \%$. The Government of Serbia are optimistic when it comes to obligations that by 2020 Serbia reached a share of $27 \%$ renewable energy in final energy consumption, given that we are currently between 23 and $24 \%$ of the first windmills have already started to revolve in Serbia and will only be rotating in the future. We now have 17 megawatts of wind farms, and in different phases of the projects we have 483 megawatts. Renewable energy, energy efficiency, use of clean energy and transport are our priorities. Also, set national targets for building new capacity from renewable is primarily implemented in the wind. - When it comes to solar power incentives prescribed by the state only for the first $10 \mathrm{MW}$. The quota has already been filled and is not expected to be an increase in the quota, by the end of 2018, by when the Decree on incentives for production of electricity from renewable sources and from highly efficient cogeneration of electricity and heat. Cadastre of small power plants from 1987 and is not binding and the relevant ministry launched a project to create a new Cadastre of MHE, the realization of which were approved funding under the IPA program, and expected that this barrier to overcome in the foreseeable future. It is necessary to further simplify administrative procedures and remove administrative barriers and, where appropriate, the work on the inclusion of procedures for issuing permits and licenses in electronic services e-government portal. In the sector of heat, the anticipated goals are not realized as planned, which is why it is necessary to improve the legislative framework and implement appropriate measures, incentives and activities that would contribute to greater use of renewable energy in this sector. When we talk about renewable energy in transport, it is necessary to work more actively to create conditions to employ local resources to produce bio fuels, but also for their placing on the market. This would increase the use of traffic, hired to local resources and foster rural development. To achieve the objective of at least $10 \%$ of RES in gross final energy consumption of the Republic of Serbia in traffic, it is necessary to think and of stimulating the use of electric vehicles. 
The biggest obstacle to greater investment in renewable energy is the lack of initial capital, which prevents investors to cover initial investment costs. Commercial loan interest rates available in the market are high, and therefore limiting. The big problem remained unsolved property relations at the locations, the lack of planning documents (spatial plan of cities and municipalities, price regulation, etc.) And often change planning documentation during the implementation of projects and slow procedures for issuing licenses and permits. These are just some of the common difficulties, and every form of renewable energy has some specific problems that arise during the implementation of projects. For example, when we talk about biomass provision of the Treaty on Long-term supply of biomass, which is one of the conditions that require banks to finance such projects, and on the other side, and that the investor provide so as not to come into a situation that one year has raw materials, a others do not. Problems in the construction of MHE are the property relations at the locations, the creditworthiness of small investors, in part slow procedure of issuing approvals, opinions and licensing, and often the lack of planning documents. Also, the problem is that the location is part of the protected areas (national parks).

\section{DEVELOPING AWARENESS OF THE IMPORTANCE OF ENVIRONMENTAL PROTECTION AT ALL LEVELS OF SOCIETY}

The economy and the environment is a topic which mostly governments, civil society and citizens. Its importance for business and decisions related to buying, as well as legislation, standards and regulations is growing all the time. The result is that no company can afford to take the environment for granted. Regardless of the industry and area of activity, the company must reduce its impact on the environment and to protect it as much as possible. As a world leader in the provision of services for environmental protection, SGS offers testing, sampling, inspection, certification, verification and comprehensive range of professional solutions in the field of environment. It's GAP analysis or survey of the current situation, at customer sites in the field of environmental protection and safety and health at work, under international standards, current legislation, technical standards and requirements of stakeholders. It is necessary to make plans, analyzes, studies and other documents in accordance with applicable legal requirements in the field of environmental protection: waste management plans, the impact assessment of projects and facilities on the environment. It is necessary to prepare documentation and requirements for obtaining IPPC permit. Then there are the EDD (Environmental due diligence), evaluation of the ecological status of the location: ESA I (Environmental Site Assessment Phase I - Data collection and reporting), ESA II (Environmental Site Assessment Phase II sampling, analysis and report that includes financial aspects).

In Serbia, the most common preparation of waste management plans, studies environmental impact assessment, strategic environmental impact assessment, waste characterization, GAP analysis, education. With regard to the standards to be adopted for Serbia joining the European Union, to develop segment of environmental protection must continue to evolve. 
Since the chapter on environmental protection at the stage of EU accession, most comprehensive and most demanding, we believe that the development go in the direction of establishing a systematic approach across all economic entities in the identification and management of impacts on water, soil and air, and according applicable international standards, raising awareness on the importance of environmental protection at all levels of society and the development of adequate competence. The EU member states insist on: Environmental Due Diligence, feasibility study on the ecological status of the site, the monitoring plan emissions of greenhouse gases; preparation of annual GHG inventory; verification of annual GHG inventory, all in accordance with European laws on reducing emissions of greenhouse gases and emissions trading scheme (EU ETS). It is realistic to expect a similar scenario and in our region.

\section{CONCLUSION}

Energy is an area which is largely dependent on the regional and even global economic and financial situation, the political situation and national legislation and in small markets such as Serbia, the situation is even more complex. Common investment cycles can be unfavorable to the company such as ours. That's why we committed to expanding the markets in which we operate, both independently and in collaboration with global consulting companies with which he has performed at the regional and international wrong. Of course, the Serbian market, and then the region is our domestic market that will always be the top priority. On the other hand, energy is an area where the financing of projects largely resolved efficiently and takes into account the risks of the project. For us, this means that charging for services rarely presents difficulties and facilitate planning. We are aware that in other areas this problem exists. Announced the major projects in the construction and reconstruction of energy infrastructure. At the European level through professional organizations in the development plans, as well as through various lists of priority projects of the Energy Community and the European Commission, the planned construction of power corridors that pass through the region of the Western Balkans. $\mathrm{We}$, as $\mathrm{E} \& \mathrm{E}$, we have participated and participate in several studies dealing with these corridors, but we are aware that the upcoming intensive activities on the realization of these projects. Also, we expect that will be part of the reconstruction of existing lines, either in the form of revitalization of old facilities or increase the transmission power of the individual lines, open up opportunities for our involvement. We have the knowledge and the resources and experience that are needed for this. In Serbia plans to progress further in terms of quality of services, gained knowledge and increase work efficiency. Invest in the education of employees and the purchase of software that will help us in this. Should certainly was that this approach to pay and we will strengthen our position in the regional market and continue on the path to become one of the leading regional companies design and consulting, which will be able to be a fully equal partner to global players in the market. 
Also, should also strengthen ties with our local, or partner and competitive companies, with whom we are joined to participate in the global market. Serbia in the energy sector still has a fully competent professional staff, a company like ours have the ability to, in cooperation with academic institutions, the quality of services provided rise to a much higher level. It is necessary to invest in skills, training, software tools and exchange of experience. This is exactly what Serbia in this field should work.

\section{REFERENCES}

[1] Stošić-Mihajlović, L. [2015]. Application of the principles of sustainable development of transport infrastructure and logistics as an economic system. Journal of Process Management. New Technologies , 3(2), 36-43.

[2] Đurić, S., \& Mihajlović, M. [2017]. Economy 'smart buildings' housing. Journal of Process Management. New Technologies , 5(1), 1-6.

[3] Stošić-Mihajlović, L. [2015]. Conditionality economic policy and economic system. Journal of Process Management. New Technologies, 3(1), 7683.

[4] Stošić Mihajlović, Lj., [2014]. Obnovljivi izvori energije, ISBN 978-86-6027-0711;502.171:620.9(075.8); COBISS.SR- 